\title{
A comparison of reproductive isolation between two closely related oak species in zones of recent and ancient secondary contact
}

Wan-Jin Liao ${ }^{1 *}$, Bi-Ru Zhu' ${ }^{1}$, Yue-Fei Li ${ }^{1}$, Xiao-Meng Li ${ }^{1}$, Yan-Fei Zeng ${ }^{2}$ and Da-Yong Zhang ${ }^{1 *}$

\begin{abstract}
Background: Much of the debate over the evolutionary consequences of hybridization on genetic divergence and speciation results from the breakdown or reinforcement of reproductive barriers in secondary hybrid zones. Among hybrid populations established for different lengths of time following secondary contact, stronger reproductive barriers are generally expected to occur in zones with longer contact. However, in plants no detailed investigation of recent and ancient zones of secondary contact has been conducted despite the importance of such a comparative study. Here, we compare pre- and postzygotic reproductive barriers between two closely related oak species, Quercus mongolica and Q. liaotungensis, in such a situation.
\end{abstract}

Results: The recorded flowering times of both species overlapped in both contact zones. The fruit set at 10 and 30 days after interspecific hand pollination was not significantly lower than that after intraspecific pollination whenever Q. mongolica or Q. liaotungensis comprised the maternal parents in both populations. These results indicated that neither prezygotic phenological barriers nor interspecific incompatibility could have resulted in the reproductive isolation between the two species in both hybrid zones. However, the proportion of hybrid seeds produced by both species in the ancient zone was significantly lower than that recorded in the recent zone of secondary contact. In addition, the proportion of hybrid seeds simulated to form, assuming both random mating and an absence of postpollination barriers, was significantly higher than that detected in the ancient contact zone but not in the recent contact zone. These results suggest stronger early-acting postzygotic isolation between the two oak species in the ancient relative to the recent contact zone.

Conclusions: Our comparative study demonstrated that postzygotic barriers during seed maturity were the main contributing factor to total reproductive isolation, particularly in the ancient contact zone, which aided species delimitation. In the recently formed secondary contact zone, pre- and postzygotic barriers were not well developed, and a high frequency of natural hybridization was evident. To our knowledge this study provides the first comparison of reproductive isolation between the ancient and recent secondary contact zones in plants and helps to clarify the evolutionary consequences of hybridization in a temporal context.

Keywords: Ancient contact zone, Hybridization, Postzygotic, Quercus, Recent secondary contact, Reproductive isolation, Temporal differentiation

\footnotetext{
*Correspondence: liaowj@bnu.edu.cn; zhangdy@bnu.edu.cn

${ }^{1}$ State Key Laboratory of Earth Surface Processes and Resource Ecology and

MOE Key Laboratory for Biodiversity Science and Ecological Engineering,

College of Life Sciences, Beijing Normal University, Beijing 100875, China

Full list of author information is available at the end of the article
}

(c) The Author(s). 2019 Open Access This article is distributed under the terms of the Creative Commons Attribution 4.0 International License (http://creativecommons.org/licenses/by/4.0/), which permits unrestricted use, distribution, and reproduction in any medium, provided you give appropriate credit to the original author(s) and the source, provide a link to the Creative Commons license, and indicate if changes were made. The Creative Commons Public Domain Dedication waiver (http://creativecommons.org/publicdomain/zero/1.0/) applies to the data made available in this article, unless otherwise stated. 


\section{Background}

Hybridization occurs in approximately one-quarter of plants [1] and plays an important role in plant speciation and gene flow among genetically distinct populations and taxa [1-5]. Theoretical and empirical studies suggest that hybridization may accelerate genetic divergence and speciation by creating genetic novelty [2-4, 6-9] or may inhibit differentiation because of the breakdown of reproductive barriers $[10,11]$. Comparisons of reproductive isolations between hybrid populations in ancient and recent secondary contact zones may help to clarify the evolutionary consequences of hybridization in a temporal context $[2,12]$. When incompletely isolated populations or taxa are in geographic contact again, reproductive barriers to gene flow may break down, leading to a reduction of genetic differentiation and even the challenge of species delimitation [13, 14]. The opposite outcome is that any reproductive barriers might be strengthened under selection against unfit hybrids $[15,16]$. Moreover, these consequences may vary among hybrid populations established for different lengths of time following secondary contact. Unfortunately, whether barriers to gene flow are strengthened or broken down in secondary contact zones remains uncertain, although theoretical and empirical evidence suggests that the breakdown of reproductive barriers is more likely [2]. Significantly, no study to our knowledge has compared barriers to reproductive isolation in ancient and recently formed plant hybrid zones.

Reproductive isolation is of central interest for understanding speciation and diversification [17-20]. An increasing number of case studies suggest that a range of pre- and postzygotic isolating barriers contribute positively to reproductive isolation between closely related taxa [12], and researchers have attempted to quantify the contribution of each barrier to reproductive isolation [20-22]. The general expectation is that prezygotic isolation is more likely to occur and contributes more to total reproductive isolation $[17,20,23]$; however, changes in species ranges may significantly erode prezygotic isolation and increase the frequency of hybridization $[2,23]$. On the other hand, postzygotic isolation is thought to be well characterized at the genetic level and prevalent $[18,20,24,25]$. If postzygotic isolation is more easily formed and strengthened as a function of genetic divergence $[20,24,26,27]$, it is reasonable to expect that postzygotic isolation would evolve more rapidly [25] and would therefore be stronger in ancient than in recent contact zones. So far, only for a few taxa that form hybrid zones have detailed analyses been conducted on the nature of pre- and postzygotic reproductive barriers, while no investigations have been conducted for most hybrid zones [12]. Furthermore, few studies have focused on the differential performance of reproductive isolation among regions in which closely related species exhibited different hybridization rates or co-occurrence history. Only one study compared the isolating barriers in Ipomopsis zones with varied hybridization rates and found that the prezygotic pollinator choice of flowers promoted different rates of hybridization [28]. Therefore, comparative studies on reproductive isolation between ancient and recently formed plant hybrid zones are crucial to understand the evolutionary consequences of hybridization in a temporal context.

Oak species are widely distributed in the Northern Hemisphere from cool temperate to tropical latitudes and show a high frequency of interspecific hybridization [12, 29-34]. Our previous studies have revealed an ancient secondary contact zone in Northeast China and a recent secondary contact zone in North China between two closely related oak species, Quercus mongolica and $Q$. liaotungensis, which provided a valuable study system for comparing the evolutionary consequences of hybridization in a temporal context [34]. We proposed that selection against hybrids may have had sufficient time to reinforce the reproductive barriers in the ancient but not in the recent secondary contact zone [34].

Here, we evaluated the evolutionary consequences of hybridization in a temporal context by comparing the pre- and postzygotic reproductive isolations between $Q$. mongolica and $Q$. liaotungensis in zones of recent and ancient secondary contact. We investigated ecological isolation by recording the flowering phenology and interspecific compatibility by following the fruit set after inter- and intraspecific hand pollination. In addition, we scored genotypes of mature seeds at seven microsatellite loci and calculated the proportion of hybrid seeds under natural and simulated pollination conditions to evaluate the postzygotic predispersal isolation. We systematically sampled individual trees throughout the populations, identified the species status of each sample, and calculated the proportion of hybrids to evaluate whether postdispersal isolation decreased the proportion of hybrids during their growth. The specific questions we addressed were: 1) Do pre- or postzygotic barriers contribute more to total reproductive isolation between $Q$. mongolica and Q. liaotungensis? and 2) Are reproductive barriers weaker in the recent secondary contact zone?

\section{Results}

\section{Flowering phenology}

The flowering phenology overlapped between the two Quercus species in both the NA (ancient) and Dlw (recent) populations, and every investigated tree had the potential to hybridize with the other species according to their flowering phenology in both the NA and Dlw populations. In 2012 in population NA, the four Q. liaotungensis trees began dispersing pollen on 17th May and 
ceased on 23rd May, whereas the three Q. mongolica trees began dispersing pollen on 18th May and ceased on 23rd May. In 2013 in population Dlw, the 16 Q. liaotungensis trees began dispersing pollen on 12th May and ceased on 18th May, whereas the seven Q. mongolica trees began dispersing pollen on 13th May and ceased on 21st May.

\section{Fruit set under intra- and interspecific pollination}

Both Q. liaotungensis and Q. mongolica were compatible when hand pollinated with interspecific pollen (Fig. 1). The full model suggested that intraspecific pollination had negative effect on the fruit set, while population had no significant effect on the fruit set (Additional file 1: Table S1). However, the interaction between population and pollination treatment indicated that intraspecific pollination significantly increased the fruit set in population NA but not in population Dlw $(P=0.001$, Additional file 1: Table S1).

The maternal species had a significant effect on the fruit set (Additional file 1: Table S1) and the interaction between maternal species and pollination treatment indicated that the fruit set following intraspecific pollination were significantly more than that following interspecific pollination when $Q$. mongolica comprised the maternal plants $(P<0.001)$. When $Q$. liaotungensis comprised the maternal plants, the interaction between population and pollination treatment suggested different scenarios in the two populations (Additional file 1: Table S1). In population NA, the fruit set following intraspecific pollination was higher than that following interspecific pollination $(P=0.002)$; while in population Dlw, the fruit set following intraspecific pollination was lower than that following interspecific pollination $(P<0.001$, Fig. 1$)$.

\section{Hybridization rate under open and simulated pollination conditions}

Both Q. liaotungensis and Q. mongolica trees produced hybrid seeds under open pollination in both populations (Fig. 2), however the proportion of hybrid seeds significantly differed between populations and between maternal species (Additional file 2: Table S2). The proportion of hybrid seeds in population NA (Q. liaotungensis: $0.263 \pm 0.036$; $Q$. mongolica: $0.275 \pm 0.060$ ) was much less than that (Q. liaotungensis in 2013 and 2014: 0.682 \pm 0.062 and $0.689 \pm 0.044 ;$ Q. mongolica: $0.885 \pm 0.036$ )

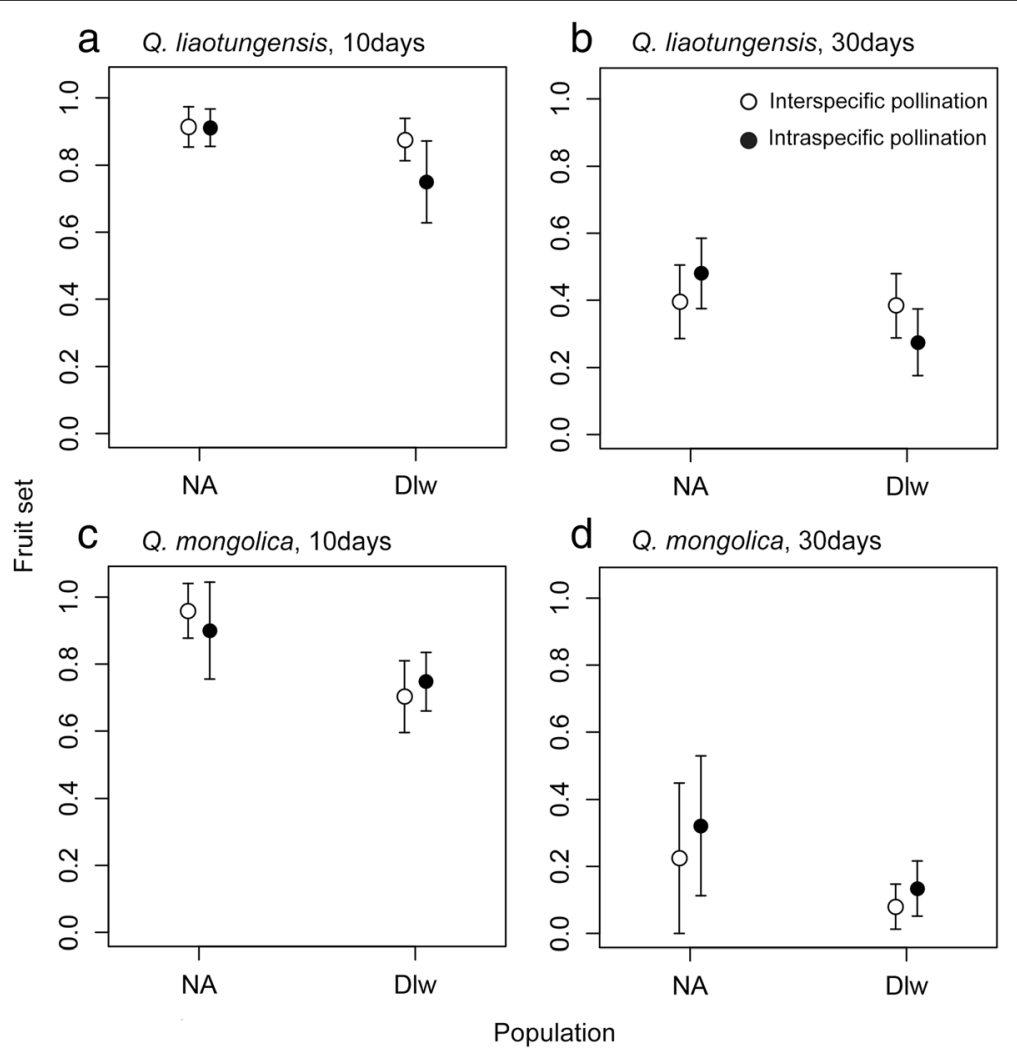

Fig. 1 Fruit set (mean \pm SE) at 10 and 30 days after inter- and intraspecific hand pollination in the ancient and recent secondary contact zone between Quercus liaotungensis and Q. mongolica. The open and solid circles represent fruit set after inter- and intraspecific pollination, respectively. Figures $\mathbf{a}$ and $\mathbf{b}$ indicate the fruit set at 10 and 30 days after pollination when $Q$. liaotungensis comprised the maternal plants, respectively, and the Figures c and $\mathbf{d}$ indicate the fruit set at 10 and 30 days after pollination when Q. mongolica comprised the maternal plants, respectively 


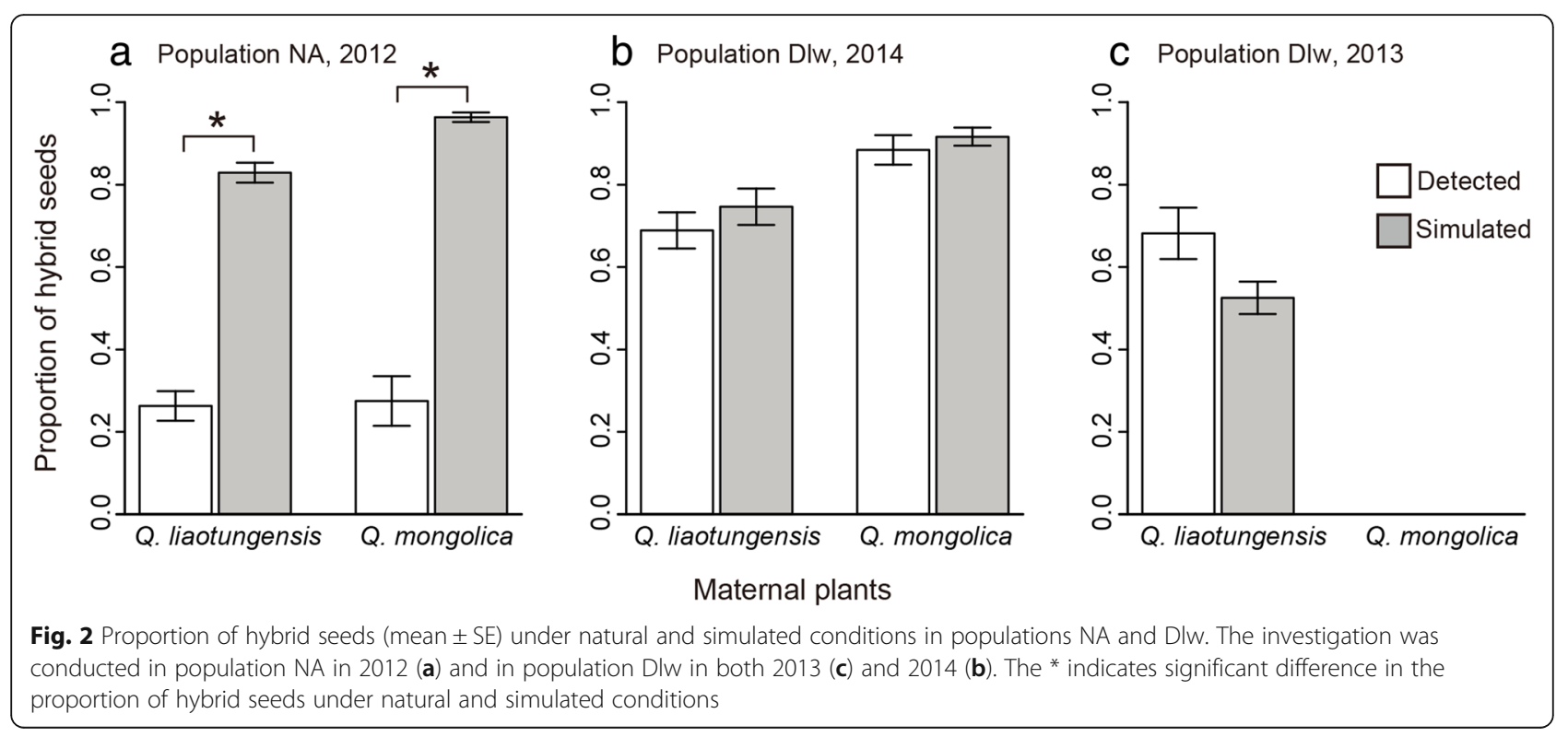

in population Dlw $(P<0.001)$. The $Q$. mongolica trees tended to have higher proportion of hybrid seeds $(P<$ $0.001)$. The interaction between population and maternal species indicated that in population NA the proportion of hybrid seeds decreased more when Q. mongolica comprised the maternal species $(P=0.001)$.

Based on the simulated seed multilocus genotypes and Bayesian analyses, the simulated proportion of hybrid seeds without postpollination barriers in 2013 in population Dlw was $0.525 \pm 0.039$ for Q. liaotungensis and in 2014 was $0.747 \pm 0.044$ for Q. liaotungensis and $0.917 \pm$ 0.022 for $Q$. mongolica. The simulated proportion of hybrid seeds was not significantly different from the detected proportion based on the molecular data set (Fig. 2). However, the simulated proportion of hybrid seeds was $0.829 \pm 0.024$ for Q. liaotungensis and $0.963 \pm$ 0.012 for Q. mongolica in population NA, both of which were significantly higher than the actual proportion of hybrid seeds for both species (Q. liaotungensis: $\mathrm{t}=19.970$, $P<0.001$; . mongolica: $\mathrm{t}=10.624, P<0.001$; Fig. 2 ).

\section{Hybrid growth costs}

Based on the assignment analyses, the individuals sampled from population NA included 80 Q. liaotungensis trees, 44 Q. mongolica trees, and 119 hybrids. Similarly, the individuals sampled from population Dlw included 59 Q. liaotungensis trees, 17 Q. mongolica trees, and 265 hybrids. The proportion of hybrid trees in population NA was 0.490 , which was significantly lower than that in population Dlw (0.777) $\left(X^{2}=50.78, \mathrm{df}=1, P<0.001\right)$. In population $\mathrm{NA}$, the diameter at breast height $(\mathrm{DBH})$ distribution of hybrids was not significantly different from that of individuals of both species (hybrid DBH: $7.00 \pm 0.21 \mathrm{~cm}$; both species $\mathrm{DBH}: 6.75 \pm 0.20 \mathrm{~cm}$; $\mathrm{D}=$
0.095, $P=0.641$ ). A similar DBH distribution was found in population Dlw (hybrid DBH: $7.35 \pm 0.25 \mathrm{~cm}$; both species $\mathrm{DBH}: 7.32 \pm 0.42 \mathrm{~cm}$; $\mathrm{D}=0.106, P=0.521)$. In both populations, logistic regression results revealed that the probability of randomly sampling a hybrid tree from the population did not decrease with increasing DBH (NA: $\mathrm{z}=0.856, P=0.392 ; \quad$ Dlw: $\mathrm{z}=$ $0.066, P=0.948$ ). Our results suggest that hybrids did not suffer increased growth costs in either the NA or Dlw population (Fig. 3).

\section{Discussion}

Our comparative study of reproductive isolation between the ancient and recent secondary contact zones of two closely related oak species revealed the absence of prezygotic phenological isolation in both contact zones. Overall, the negative effect of intraspecific pollination on fruit set indicated the compatibility of hybridization between the two oak species. However, the interaction between population and pollination treatment indicated that the fruit set after intraspecific pollen was significantly more than that after interspecific pollen in population NA but not in population Dlw, which suggested that some mechanisms during seed maturation were responsible for aborting the hybrid embryos in the ancient but not recent hybridization zone. Moreover, the proportion of hybrid seeds produced by both species in the ancient zone was significantly lower than that in the recent zone of secondary contact. The proportion of hybrid seeds simulated to form, assuming both random mating and an absence of postpollination barriers, was significantly higher than the proportion actually detected in the ancient zone, but not in the recent zone. These results suggest significantly stronger early-acting postzygotic 
a Population NA

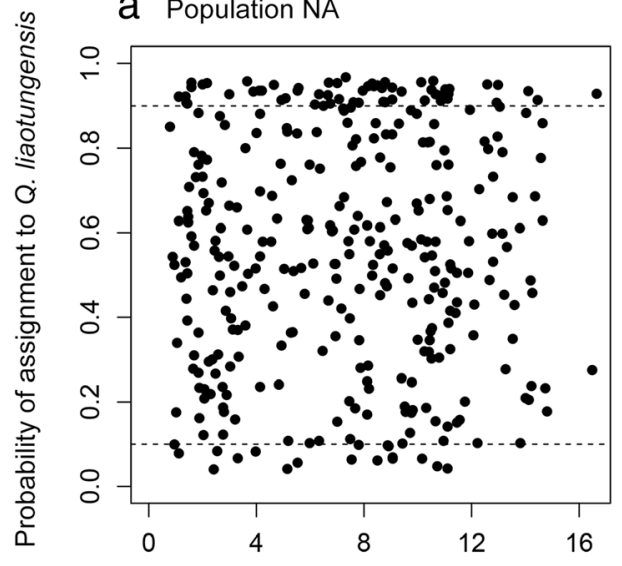

b Population DIw

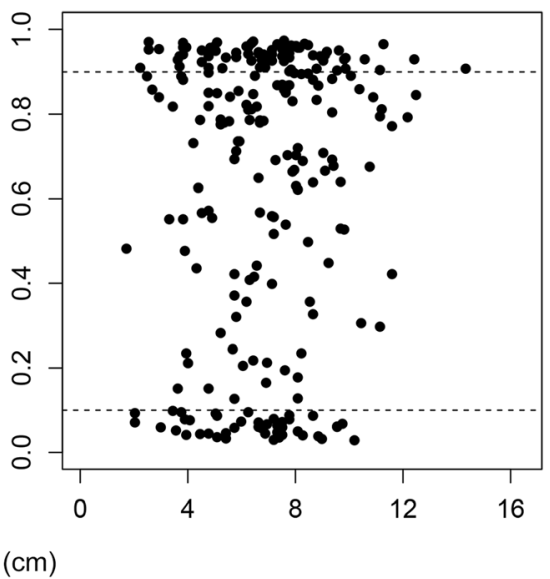

Fig. 3 Relationship between tree diameter at breast height $(\mathrm{DBH})$ and the probability of a tree being assigned to $\mathrm{Q}$. liaotungensis in populations NA (a) and Dlw (b). The dashed lines indicate the cut-off value of 0.9. Scatter points above the 0.9 dashed line represent Q. liaotungensis trees, scatter points beneath the 0.1 dashed line represent $Q$. mongolica trees, and scatter points between the two lines represent the hybrid trees

isolation between the two oak species in the ancient relative to the recent secondary contact zone.

Prezygotic barriers are usually thought to contribute more to total reproductive isolation than postzygotic barriers in natural populations because prezygotic barriers reduce interspecific pollen transfer [17, 20]. In secondary contact zones, reinforcement selection suggests that traits capable of increasing prezygotic isolation could evolve and be reinforced to select against unfit hybrids [15, 35]. However, a recent review has speculated that prezygotic barriers could be more easily eroded under global change than postzygotic barriers [23]. When closely related species come into contact, geographical and phenological barriers may be eroded, which can lead to a degradation of prezygotic isolation in secondary contact zones [23, 36, 37]. In our study, we found no evidence for the phenological isolation because flowering time overlapped between the two oak species in both contact zones. Moreover, interspecific pollinations were compatible in both Quercus species because the full statistics model indicated that the fruit set after interspecific pollination was not less than that after intraspecific pollination (Fig. 1, Additional file 1: Table $\mathrm{S} 1$ ). When hybridization was fully compatible, it is not unusual to expect that intraspecific pollination may decrease the fruit set because the intraspecific pollen donors were more closely related to the pollen receptors than interspecific pollen donors.

Compared with prezygotic barriers, postzygotic barriers would be expected to be stronger in the ancient contact zone of two oak species, if postzygotic isolation are more intense between more diverged lineages $[26,27]$. Based on the differences in genetic divergence and co-occurrence history between $Q$. mongolica and Q. liaotungensis [31, 34, 38], we expected to observe stronger postzygotic barriers in the ancient contact zone than in the recent contact zone. Because interspecific fertilization was compatible in both species, the abortion of hybrid embryos may lead to a reduced hybrid seed set [17]. Our results from hand pollination and natural hybridization were consistent with these expectations. First, the interaction between population and pollination treatment indicated that the fruit set after intraspecific pollination was significantly more than that after interspecific pollination in population NA but not in population Dlw, whenever Q. mongolica or Q. liaotungensis comprised the maternal species (Fig. 1, Additional file 1: Table S1). Second, the proportion of hybrid seeds under natural pollination in the ancient contact zone was much lower than that in the recent contact zone (Fig. 2). The proportion of hybrid seeds in the recent contact zone was $0.885 \pm 0.036$ for Q. mongolica and $0.682 \pm 0.062$ (2013) and $0.689 \pm 0.044$ (2014) for Q. liaotungensis, while the proportion was sharply reduced to less than $30 \%$ in the ancient contact zone (Fig. 2). Both the results suggested stronger early-acting postzygotic barriers in the ancient contact zone.

The relative abundance and spatial distribution of parent species and hybrid trees would influence the proportion of hybrid seeds in the same population [5]. To distinguish the effects of relative abundance on the production of hybrid seeds, we simulated the seed genotypes without any postpollination barriers using HYBRIDLAB and found that the simulated proportion of hybrid seeds was similar to the proportion obtained under natural conditions in the recent contact zone when $Q$. mongolica and Q. liaotungensis comprised the 
maternal plants (Fig. 2). However, the simulated proportion of hybrid seeds was much higher than the proportion under natural conditions in the ancient contact zone (Fig. 2). Therefore, the significantly lower proportion of hybrid seeds under natural conditions compared with simulated conditions in the ancient contact zone largely resulted from the abortion of fertilized embryos during the development of seeds. Collectively, these results are consistent with the expectation that stronger postzygotic barriers had a stronger inhibitory effect on hybridization in the ancient contact zone compared with the recent secondary contact zone because selection against hybrids had sufficient time to strengthen the postzygotic isolation between $Q$. mongolica and $Q$. liaotungensis in the ancient but not in the recent secondary contact zone.

Reduced hybrid viability and fertility often occur because of postzygotic barriers, even when hybrid seed matures, as detected in certain plants [39, 40]. For example, the $\mathrm{F}_{1}$ hybrids of Trillium tschonoskii as the maternal parent and T. camschatcense as the paternal parent failed to reach maturity [41], and the germination rates of hybrid seeds between Quercus robur and $Q$. petraea were reduced [42]. In the present study, we found that the probability of sampling a hybrid tree did not decrease with increasing DBH in both the ancient and recent secondary contact zones (Fig. 3). Our results suggest that hybrid trees did not show an increase in mortality during their growth and postzygotic barriers did not occur after germination if DBH was assumed to increase with the growth of the oak trees. The high frequency of hybrid trees in the contact zone of the two oak species has caused taxonomic confusion as indicated by the difficulty in distinguishing hybrid trees from parental oak trees [38].

\section{Conclusions}

Our study provides the first comparison of reproductive isolation between ancient and recent secondary contact zones of two closely related oak species. The results demonstrate that postzygotic barriers during seed maturity account for the largest contribution to the total reproductive isolation between the two species, particularly in the ancient contact zone, thereby maintaining the species integrity. In the recent secondary contact zone, neither pre- nor postzygotic barriers were well developed, which led to a high frequency of natural hybridization and morphological and taxonomic confusion.

\section{Methods}

\section{Study system}

Quercus liaotungensis Koidz. and Q. mongolica Fisch. Ex Ledeb. (Fagaceae) are two closely related oak species of temperate broadleaved forests in China [31]. These oaks are monoecious and wind pollinated. Male catkins are solitary in leaf axils towards the base of branchlets or in paniculate clusters on lateral or subterminal shoots, and female flowers are scattered in leaf axils on the apical part of young shoots. The two species are sympatric in certain areas of North and Northeast China, although the range of $Q$. liaotungensis extends farther west into West China, and the range of Q. mongolica extends farther north into Russia and east into Korea, South Korea and Japan [31,34]. Our study was conducted in populations NA $\left(44^{\circ} 21^{\prime} \mathrm{N}, 129^{\circ} 32^{\prime} \mathrm{E}\right)$ and Dlw $\left(39^{\circ} 58^{\prime} \mathrm{N}, 115^{\circ}\right.$ $26^{\prime}$ E) described in Zeng et al. [34]. A previous study suggested that the NA and Dlw populations are located in ancient and recent secondary hybridization zones, respectively. All the plant materials involved in this study were identified by Prof. Wan-Jin Liao and Yan-Fei Zeng and the voucher specimens were deposited in Beijing Normal University.

\section{Genotype scoring and individual assignment}

We collected buds, seeds, and leaves to identify the species status of each individual because hybridization between the two oak species generated morphologically intermediate individuals and hence the two species cannot be straightforward distinguished from each other based on morphological traits [38]. All the materials were sampled from natural populations and no specific permission was needed to collect such samples. Genomic DNA was extracted from each bud, seed, or leaf using an N96 Plant Genomic DNA Kit (Tiangen, Beijing, China). Of the 19 nuclear SSR (simple sequence repeat) loci [31], we scored the following 7 loci with the highest power to distinguish the two oak species: ssrQpZAG36, ssrQpZAG15, ssrQpZAG110, quru-GA-0 M07, ssrQrZAG87, ssrQrZAG101, and ssrQrZAG112. The PCR amplification followed the procedures described in Zeng et al. [31]. The labeled PCR products were analyzed on an Applied Biosystems 3730 Genetic Analyzer with a LIZ500 size standard (Applied Biosystems, Grand Island, New York, USA) and the SSR genotyping was scored using GeneMapper v3.7 (Applied Biosystems, Grand Island, New York, USA).

Because no species-specific loci were detected [31], we used a Bayesian clustering method in STRUCTURE 2.3.4 [43] to identify each individual with Q. mongolica, $Q$. liaotungensis, or mixed ancestry. The datasets used in these assignment analyses included two parts: one was the 7-locus SSR data of individuals studied in Zeng et al. [34] (defined as preset data), and the other was the 7-locus SSR data of individuals we scored in the present study (defined as new data). Individuals from populations Dlw and NA were analyzed separately. In the analysis of individuals from population Dlw, the preset data included all individuals from the 38 populations studied 
in Zeng et al. [34]. In the analysis of individuals from population NA, the preset data included individuals from 28 populations. The 10 Q. liaotungensis populations from Zeng et al. [34] located in Northwest-North China were excluded because Q. liaotungensis populations from Northwest-North China and Northeast China are significantly genetically differentiated [34]. The program was run for $K=2$ to detect the probability $(Q)$ of each individual being assigned to the two clusters (two species: Q. mongolica and Q. liaotungensis) without prior population information. We assumed correlated allele frequencies and an admixed origin of populations. The burn-in was set to 50,000 and the run length was set to 200,000 . Ten replicates were analyzed, and the results for the same data set were summarized by CLUMPP [44]. When the probability assigned to one cluster was greater than 0.9 , we defined the individual belonging to that species; otherwise, the individual was a hybrid between the two species. The cut-off value was set to 0.85 only for the hand pollination experiments to obtain more parental plants.

\section{Flowering phenology}

We recorded the flowering phenology in populations $\mathrm{NA}$ and Dlw to investigate whether differentiation in flowering phenology prevented hybridization between the two oak species. In late April of 2012 and 2013, we collected buds from 30 oak trees in population NA and 78 oak trees in population Dlw, respectively. Based on the assignment described above, we chose four $Q$. liaotungensis trees and three Q. mongolica trees in population NA in 2012 and recorded the pollen dispersal of each tree from 15th May to 25th May, and in population Dlw, we chose 16 Q. liaotungensis trees and seven $Q$. mongolica trees in 2013 to record the duration of pollen dispersal from the 10th to the 25th of May. We checked almost all flowers on each observed tree each day and recorded whether flowers dispersed pollen until the dispersal of pollen ceased for almost all flowers.

\section{Hand pollination experiments}

We conducted hand pollination experiments to investigate whether interspecific pollination incompatibility prevented hybridization between the two oak species. Based on the assignment results, we chose six $Q$. liaotungensis trees and two Q. mongolica trees as maternal plants in population NA in 2012. From the six $Q$. liaotungensis trees, we randomly selected 281 female flowers from 42 lateral branches for interspecific hand pollination and 438 female flowers from 54 branches for intraspecific hand pollination. We removed all male catkins from the chosen terminal branches in the early development stage of the male catkins and bagged all female flowers approximately 5 days before the stigmas were receptive. We also bagged a number of male catkins and collected pollen grains for hand pollination. When female flowers were receptive, we brushed the collected pollen on the stigmas. To reduce the potential pollen contamination from the air, we used an unused, large plastic bag to rebag the chosen terminal branches, and we performed the hand pollination in this bag. The bags were removed 7 days after hand pollination. From the two Q. mongolica maternal trees, 23 female flowers from seven branches and 35 female flowers from 15 branches were hand pollinated with inter- and intraspecific pollen, respectively.

In population Dlw, we chose five Q. liaotungensis trees and 11 Q. mongolica trees as maternal plants for hand pollination in 2013. From the five Q. liaotungensis trees, we chose 418 female flowers from 31 branches and 209 female flowers from 22 branches for the inter- and intraspecific hand pollination, respectively. From the $11 Q$. mongolica trees, we chose 304 female flowers from 33 branches and 321 female flowers from 39 branches for the inter- and intraspecific hand pollination, respectively. We counted the number of developing and aborted ovaries from each branch at 10 and 30 days after hand pollination and calculated the fruit set as the number of developing ovaries divided by the number of female flowers on each branch that we hand pollinated.

We evaluated the effects of hand pollination treatment, maternal species, and population on fruit set by fitting generalized linear mixed models (GLMMs) with a binomial distribution and logit link function using lme4 [45]. Within this model, the number of developing and aborted ovaries were responsible variables, the hand pollination treatment, maternal species, and population were set as the fixed factors with full interactions, and the maternal trees and measurement time were set as the random factors.

\section{Detecting hybrid seeds under open and simulated pollination conditions}

To estimate the proportion of hybrid seeds under natural pollination, we collected seeds from individuals of pure species for SSR genotyping and species assignment. Based on the cut-off value of 0.9 , we identified $17 Q$. liaotungensis and 10 Q. mongolica trees in population NA in 2012, 4 Q. liaotungensis trees in population Dlw in 2013, and 5 Q. liaotungensis and 4 Q. mongolica trees in population Dlw in 2014. We attempted to collect more than 30 fruits from each of the chosen pure oak trees, and we extracted the genomic DNA from each embryo for the subsequent SSR genotyping. Finally, we identified each seed as an individual of $Q$. liaotungensis or Q. mongolica or as a hybrid according to the SSR genotype assignment analysis described above with a cut-off value of 0.9 . The seed was assumed to originate 
from intraspecific pollination when both the seed and the maternal oak tree were assigned to the same species, and was considered a pure seed; otherwise, the seed was considered a hybrid seed. The proportion of hybrid seeds was calculated as the number of seeds fertilized by non-intraspecific pollen divided by the number of seeds scored for each tree. In total, 785 seeds were scored from population NA and 253 seeds were scored from population Dlw.

To investigate the effects of maternal species and population on the proportion of hybrid seeds under natural pollination, we fitted generalized linear mixed models (GLMMs) with a binomial distribution and logit link function. Within this model, the number of hybrid seeds and pure seeds were responsible variables, the maternal species and population were set as the fixed factors with interaction, and the year was the random factor.

To evaluate the expected proportion of hybrid seeds without any postpollination barriers in each population, we used HYBRIDLAB [46] to generate seed genotypes for each sampled mother tree. For each population, the seed genotypes were simulated separately for each mother tree as follows. The mother trees that we sampled to detect the hybrid seeds under natural pollination were set as parental 1 , and all other trees with $\mathrm{DBH}>5 \mathrm{~cm}$ (described in the following "Hybrid growth costs" section) were assumed to have the ability to fertilize and thus were set as parental 2. A total of 30 genotypes of the $F_{1}$ offspring were generated by simulating random mating between parental 1 and 2 . The same assignment analyses were applied to each of the simulated offspring to identify their species status, and the proportion of simulated hybrid seeds was calculated under random mating for each mother tree. We used paired t-tests to test whether the real proportion of hybrid seeds under natural pollination differed from the simulated proportion of hybrid seeds under random mating.

\section{Hybrid growth costs}

To evaluate whether the hybrids had an increased growth disadvantage, we sampled the oak trees in populations NA and Dlw. We assumed that the tree diameter will increase with age, and we measured the DBH as an index of tree age. In each population, we adopted a grid-sampling method and collected samples every five meters from both large and small trees. We collected one leaf from each tree and sampled 243 trees in population NA and 341 trees in population Dlw. All the sampled individuals of each population were subjected to SSR genotype scoring and assignment analyses to identify the species status. We expected that the proportion of individual trees that were hybrids would decrease with tree age if hybrid offspring suffered serious disadvantages during their growth.

To evaluate whether growth costs increased with hybrid growth, we first used a two-sample KolmogorovSmirnov test to determine whether the DBHs of the hybrids and parental species individuals were drawn from the same distribution. Then, we tested whether the probability of randomly sampling a hybrid tree from a population would decrease with increasing DBH. Based on the assignment analyses of the randomly sampled trees in each population, we valued the hybrid individuals as 1 and the individuals representing the parental species as 0 , and modeled these $1 / 0$ data by fitting a logistic regression with DBH as the explanatory variable. All statistical analyses were conducted using R [47].

\section{Additional files}

Additional file 1: Table S1. The generalized linear mixed models for fruit set. We simplified the full model by dropping the insignificant variables or interaction until no more could be dropped. We compared full model with simplified models by analysis of deviance. NA: population NA, intra: intraspecific pollination, QM: Quercus mongolica. (DOCX 17 kb)

Additional file 2: Table S2. The generalized linear mixed model for proportion of hybrid seeds. NA: population NA, QM: Quercus mongolica. (DOCX $15 \mathrm{~kb})$

\section{Abbreviation}

DBH: Diameter at breast height

\section{Acknowledgements}

We thank Prof. Spencer $\mathrm{CH}$ Barrett for his constructive comments on this manuscript.

\section{Funding}

This work was financially supported by the National Key R\&D Program of China (2017YFA0605100), the National Natural Science Foundation of China $(31370398,31270701)$ and the State Key Laboratory of Earth Surface Processes and Resource Ecology (2017-FX-05). The funders had no role in study design, data collection and analysis, decision to publish, or preparation of the manuscript.

\section{Availability of data and materials}

The datasets used and/or analyzed during the current study are available from the corresponding author on reasonable request.

\section{Authors' contributions}

LW, ZY and ZD planned and designed the research. LW, ZB, LY and LX performed the field investigations. $L W$ and $L Y$ conducted the molecular analyses. ZB and ZY analyzed the data. LW, ZB, ZY and ZD wrote the manuscript. All authors read and approved the final manuscript.

\section{Ethics approval and consent to participate}

All the plant materials were sampled from natural populations in North and Northeast China and no specific permission was needed to collect such samples. This study was conducted in accordance with local legislation and the Convention on the Trade in Endangered Species of Wild Fauna and Flora.

Consent for publication

Not applicable.

Competing interests

The authors declare that they have no competing interests. 


\section{Publisher's Note}

Springer Nature remains neutral with regard to jurisdictional claims in published maps and institutional affiliations.

\section{Author details \\ 'State Key Laboratory of Earth Surface Processes and Resource Ecology and MOE Key Laboratory for Biodiversity Science and Ecological Engineering, College of Life Sciences, Beijing Normal University, Beijing 100875, China. ${ }^{2}$ Key Laboratory of Tree Breeding and Cultivation of the State Forestry Administration, Research Institute of Forestry, Chinese Academy of Forestry, Beijing 100091, China.}

Received: 11 July 2018 Accepted: 22 February 2019 Published online: 06 March 2019

\section{References}

1. Mallet J. Hybrid speciation. Nature. 2007:446:279-83 https://doi.org/10.1038/ nature05706.

2. Abbott R, Albach D, Ansell S, Arntzen JW, Baird SJE, Bierne N, et al. Hybridization and speciation. J Evol Biol. 2013;26:229-46 https://doi.org/10. 1111/j.1420-9101.2012.02599.x.

3. Rieseberg LH. Hybrid origins of plant species. Annu Rev Ecol Syst. 1997;28: 359-89 https://doi.org/10.1146/annurev.ecolsys.28.1.359.

4. Seehausen O. Hybridization and adaptive radiation. Trends Ecol Evol. 2004 19:198-207 https://doi.org/10.1016/j.tree.2004.01.003.

5. Klein EK, Lagache-Navarro L, Petit RJ. Demographic and spatial determinants of hybridization rate. J Ecol. 2017;105:29-38 https://doi.org/10.1111/13652745.12674.

6. Rieseberg LH, Raymond O, Rosenthal DM, Lai Z, Livingstone K, Nakazato T, et al. Major ecological transitions in wild sunflowers facilitated by hybridization. Science. 2003;301:1211-6 https://doi.org/10.1126/science.1086949.

7. Stelkens RB, Brockhurst MA, Hurst GDD, Greig D. Hybridization facilitates evolutionary rescue. Evol Appl. 2014;7:1209-17 https://doi.org/10.1111/eva. 12214.

8. Pfennig KS, Kelly AL, Pierce AA. Hybridization as a facilitator of species range expansion. Proc R Soc B-Biol Sci. 2016;283:20161329 https://doi.org/10.1098/ rspb.2016.1329.

9. Hovick SM, Whitney KD. Hybridisation is associated with increased fecundity and size in invasive taxa: meta-analytic support for the hybridisation-invasion hypothesis. Ecol Lett. 2014;17:1464-77 https://doi.org/10.1111/ele.12355.

10. Levin DA, Francisco-Ortega J, Jansen RK. Hybridization and the extinction of rare plant species. Conserv Biol. 1996;10:10-6 https://doi.org/10.1046/j.15231739.1996.10010010.x.

11. Soltis PS. Hybridization, speciation and novelty. J Evol Biol. 2013;26:291-3 https://doi.org/10.1111/jeb.12095.

12. Abbott RJ. Plant speciation across environmental gradients and the occurrence and nature of hybrid zones. J Syst Evol. 2017;55:238-58 https://doi.org/10.1111/jse.12267.

13. Li Y, Tada F, Yamashiro T, Maki M. Long-term persisting hybrid swarm and geographic difference in hybridization pattern: genetic consequences of secondary contact between two Vincetoxicum species (ApocynaceaeAsclepiadoideae). BMC Evol Biol. 2016;16(20) https://doi.org/10.1186/s12862016-0587-2.

14. Zitari A, Scopece G, Helal AN, Widmer A, Cozzolino S. Is floral divergence sufficient to maintain species boundaries upon secondary contact in Mediterranean food-deceptive orchids? Heredity. 2012;108:219-28 https://doi.org/10.1038/hdy.2011.61.

15. Hopkins R. Reinforcement in plants. New Phytol. 2013;197:1095-103 https://doi.org/10.1111/nph.12119.

16. Hoskin CJ, Higgie M, McDonald KR, Moritz C. Reinforcement drives rapid allopatric speciation. Nature. 2005;437:1353-6 https://doi.org/10.1038/ nature04004.

17. Baack E, Melo MC, Rieseberg LH, Ortiz-Barrientos D. The origins of reproductive isolation in plants. New Phytol. 2015;207:968-84 https://doi. org/10.1111/nph.13424.

18. Widmer A, Lexer C, Cozzolino S. Evolution of reproductive isolation in plants. Heredity. 2009;102:31-8 https://doi.org/10.1038/hdy.2008.69.

19. Zhang WL, Gao JY. Multiple factors contribute to reproductive isolation between two co-existing Habenaria species (Orchidaceae). PLoS One. 2017; 12:e0188594 https://doi.org/10.1371/journal.pone.0188594.
20. Lowry DB, Modliszewski JL, Wright KM, Wu CA, Willis JH. The strength and genetic basis of reproductive isolating barriers in flowering plants. Philos Trans R Soc B- Biol Sci. 2008;363:3009-21 https://doi.org/10.1098/rstb.2008.0064.

21. Ramsey J, Bradshaw HD, Schemske DW. Components of reproductive isolation between the monkeyflowers Mimulus lewisii and M. cardinalis (Phrymaceae). Evolution. 2003;57:1520-34 https://doi.org/10.1111/j.00143820.2003.tb00360.x

22. Husband BC, Sabara HA. Reproductive isolation between autotetraploids and their diploid progenitors in fireweed, Chamerion angustifolium (Onagraceae). New Phytol. 2004;161:703-13 https://doi.org/10.1046/j.14698137.2003.00998.x.

23. Vallejo-Marin M, Hiscock SJ. Hybridization and hybrid speciation under global change. New Phytol. 2016;211:1170-87 https://doi.org/10.1111/nph 14004.

24. Rieseberg LH, Blackman BK. Speciation genes in plants. Ann Bot. 2010;106: 439-55 https://doi.org/10.1093/aob/mcq126.

25. Jewell C, Papineau AD, Freyre $R$, Moyle LC. Patterns of reproductive isolation in Nolana (Chilean bellflower). Evolution. 2012;66:2628-36 https://doi.org/10. 1111/j.1558-5646.2012.01607x.

26. Moyle LC, Olson MS, Tiffin P. Patterns of reproductive isolation in three angiosperm genera. Evolution. 2004;58:1195-208 https://doi.org/10.1111/j. 0014-3820.2004.tb01700.x

27. Scopece G, Musacchio A, Widmer A, Cozzolino S. Patterns of reproductive isolation in Mediterranean deceptive orchids. Evolution. 2007;61:2623-42 https://doi.org/10.1111/j.1558-5646.2007.00231.x.

28. Aldridge G, Campbell DR. Genetic and morphological patterns show variation in frequency of hybrids between Ipomopsis (Polemoniaceae) zones of sympatry. Heredity. 2009;102:257-65 https://doi.org/10.1038/hdy.2008.112.

29. Fortini P, Di Marzio P, Di Pietro R. Differentiation and hybridization of Quercus frainetto, Q. petraea, and Q. pubescens (Fagaceae): insights from macro-morphological leaf traits and molecular data. Plant Syst Evol. 2015; 301:375-85 https://doi.org/10.1007/s00606-014-1080-2.

30. Tamaki I, Okada M. Genetic admixing of two evergreen oaks, Quercus acuta and Q. sessilifolia (subgenus Cyclobalanopsis), is the result of interspecific introgressive hybridization. Tree Genet Genomes. 2014;10:989-99 https://doi.org/10.1007/s11295-014-0737-x

31. Zeng YF, Liao WJ, Petit RJ, Zhang DY. Exploring species limits in two closely related Chinese oaks. PLoS One. 2010;5:e15529 https://doi.org/10.1371/ journal.pone.0015529.

32. Leroy T, Roux C, Villate L, Bodenes C, Romiguier J, Paiva JAP, et al. Extensive recent secondary contacts between four European white oak species. New Phytol. 2017:214:865-78 https://doi.org/10.1111/nph.14413.

33. Ortego J, Gugger PF, Sork VL. Impacts of human-induced environmental disturbances on hybridization between two ecologically differentiated Californian oak species. New Phytol. 2017:213:942-55 https://doi.org/10.1111/nph.14182.

34. Zeng YF, Liao WJ, Petit RJ, Zhang DY. Geographic variation in the structure of oak hybrid zones provides insights into the dynamics of speciation. Mol Ecol. 2011;20:4995-5011 https://doi.org/10.1111/j.1365-294X.2011.05354.x.

35. Servedio MR, Noor MAF. The role of reinforcement in speciation: theory and data. Annu Rev Ecol Evol Syst. 2003;34:339-64 https://doi.org/10.1146/ annurev.ecolsys.34.011802.132412.

36. Buggs RJA. Empirical study of hybrid zone movement. Heredity. 2007;99: 301-12 https://doi.org/10.1038/sj.hdy.6800997.

37. Brennan AC, Woodward G, Seehausen O, Munoz-Fuentes V, Moritz C, Guelmami A, et al. Hybridization due to changing species distributions: adding problems or solutions to conservation of biodiversity during global change? Evol Ecol Res. 2014;16:475-91.

38. Wei L, Li YF, Zhang H, Liao WJ. Variation in morphological traits in a recent hybrid zone between closely related Quercus liaotungensis and Q. mongolica (Fagaceae). J Plant Ecol. 2015;8:224-9 https://doi.org/10.1093/jpe/rtv023.

39. Ouyang $Y$, Zhang Q. Understanding reproductive isolation based on the rice model. Annu Rev Plant Biol. 2013;64:111-35 https://doi.org/10.1146/ annurev-arplant-050312-120205.

40. Scopece G, Lexer C, Widmer A, Cozzolino S. Polymorphism of postmating reproductive isolation within plant species. Taxon. 2010;59:1367-74.

41. Ishizaki S, Abe T, Ohara M. Mechanisms of reproductive isolation of interspecific hybridization between Trillium camschatcense and T.tschonoskii (Melanthiaceae). Plant Spec Biol. 2013;28:204-14 https://doi.org/10.1111/j. 1442-1984.2012.00378.x.

42. Abadie P, Roussel G, Dencausse B, Bonnet C, Bertocchi E, Louvet JM, et al. Strength, diversity and plasticity of postmating reproductive barriers 
between two hybridizing oak species (Quercus robur L. and Quercus petraea (Matt) Liebl.). J Evol Biol. 2012;25:157-73 https://doi.org/10.1111/j.1420-9101. 2011.02414.x.

43. Pritchard JK, Stephens M, Donnelly P. Inference of population structure using multilocus genotype data. Genetics. 2000;155:945-59.

44. Jakobsson M, Rosenberg NA. CLUMPP: a cluster matching and permutation program for dealing with label switching and multimodality in analysis of population structure. Bioinformatics. 2007;23:1801-6 https:/doi.org/10.1093/ bioinformatics/btm233.

45. Bates D, Maechler M, Bolker BM, Walker SC. Fitting linear mixed-effects models using Ime4. J Stat Softw. 2015;67:1-48 https://doi.org/10.18637/jss. v067.i01.

46. Nielsen EE, Bach LA, Kotlicki P. HYBRIDLAB (version 1.0): a program for generating simulated hybrids from population samples. Mol Ecol Notes. 2006;6:971-3 https://doi.org/10.1111/j.1471-8286.2006.01433.x

47. R Core Team. R: a language and environment for statistical computing. Vienna: R Foundation for statistical Computing; 2015.

Ready to submit your research? Choose BMC and benefit from:

- fast, convenient online submission

- thorough peer review by experienced researchers in your field

- rapid publication on acceptance

- support for research data, including large and complex data types

- gold Open Access which fosters wider collaboration and increased citations

- maximum visibility for your research: over $100 \mathrm{M}$ website views per year

At BMC, research is always in progress.

Learn more biomedcentral.com/submissions 